\title{
O esporte e a modernidade em São Paulo: práticas corporais no fim do século XIX e início do XX
}

Edivaldo Gois Júnior*

\begin{abstract}
Resumo: O objetivo deste estudo foi entender como os esportes foram apropriados no Brasil, particularmente na cidade de São Paulo no fim do século XIX e início do século $\mathrm{XX}$. Para isto, utilizou como fontes: jornais e revistas que tematizaram o esporte no período estudado. Concluiu que no contexto cultural brasileiro os esportes foram ressignificados, mesmo tendo como parâmetro a modernidade europeia.
\end{abstract}

Palavras-chave: História. Esporte. Brasil. São Paulo.

\section{INTRODUÇÃo}

Foi na Inglaterra do século XIX que o termo "sport" ganhou repercussão. Constituía-se como uma nova prática corporal definida por uma série de jogos identificados com a aristocracia inglesa das "public schools".

Dentro deste contexto, os esportes opunham-se aos jogos populares, com regras que controlavam a violência e incutiam uma educação moral de respeito às normas. Elas deviam ser seguidas de forma rígida, pois o ensino da disciplina e do autocontrole moldaria o caráter do aluno, ensinando valores como justiça, obediência, disciplina, competição e cooperação. (DUNNING; ELIAS, 1992)

\footnotetext{
"Professor do Departamento de Educação Física e Humanidades e do Programa de PósGraduação em Educação Física da UNICAMP, Campinas, SP, Brasil. E-mail: edivaldo@fef.unicamp.br
} 
Essas práticas foram disseminadas culturalmente da Inglaterra para outros países da Europa e do mundo. Entender como os esportes foram apropriados no Brasil, em específico, na cidade de São Paulo no fim do século XIX e início do século XX é o objetivo deste estudo. Para tanto, utilizaremos o modelo de análise de Pierre Bourdieu sobre a constituição do "campo" e do conceito de "habitus", com o intuito de interrogar as fontes sobre os esportes no contexto da cidade.

Essa operação exige o esclarecimento de certos limites, pois temos que compreender que os objetivos específicos de Pierre Bourdieu são ligados aos interesses da Sociologia. Em seu modelo de análise sociológica é importante revelar o que ele chamou de "fundamentos da dominação oculta". Em outras palavras, ele teve como objeto a relação entre uma estrutura material e as representações dos agentes sociais. São impreteríveis ao modelo de análise de Bourdieu as descrições dos mecanismos de reprodução, as "leis de reprodução social" que se explicam em suas estruturas econômicas, mas ao mesmo tempo, nas dimensões simbólicas dos agentes sociais. Assim a sociologia seria a "ciência das lutas pelo poder". Em seus termos:

[...] poderia resumir em uma frase toda a análise que estou propondo hoje: de um lado as estruturas objetivas que o sociólogo constrói no momento objetivista, descartando as representações subjetivas dos agentes, são o fundamento das representações subjetivas e constituem as coações estruturais que pesam nas interações; mas de outro lado, essas representações devem ser retidas, sobretudo se quisermos explicar as lutas cotidianas, individuais ou coletivas, que visam transformar ou conservar essas estruturas. (BOURDIEU, 1990, p. 152)

Desse modo a narrativa desta pesquisa historiográfica terá também como objeto as relações de poder entre a estrutura e os sujeitos históricos, ou nos termos de Bourdieu, os "agentes sociais". Faz-se necessária esta explicação, já que a historiografia pode ter outros objetivos que não relacionados às estruturas, mas sim, às especificidades culturais e locais de determinado grupo, em determinado tempo, ou ainda, interessada só pelas estruturas, 
interpretar a história do esporte a partir da história política e econômica. Isto explica também a cobrança que Bourdieu faz aos historiadores do esporte no fim da década de 1970. Em seus termos:

Se for verdade, como minha interrogação parece sugerir, que o sistema de instituições e de agentes vinculados ao esporte tende a funcionar como um campo, segue-se daí que não se pode compreender diretamente os fenômenos esportivos num dado momento, num dado ambiente social, colocando-os em relação direta com as condições econômicas e sociais das sociedades correspondentes: a história do esporte é uma história relativamente autônoma que, mesmo estando articulada com os grandes acontecimentos da história econômica e política, tem seu próprio tempo, suas próprias leis de evolução, suas próprias crises, em suma, sua cronologia especifica. (BOURDIEU, 2011a, p. 174175)

Bourdieu (2011a) coloca aos especialistas a possibilidade de compreensão do esporte à luz de sua teoria sobre "a constituição dos campos". Entendendo o esporte como um campo, ele estaria suscetível às disputas e interesses específicos de diferentes agentes e grupos sociais em confronto. Desse modo, o campo seria o "locus" onde as representações subjetivas e as condicionantes estruturais transparecem na luta por um capital específico. Mas para garantir a "constituição de campo", além de um capital e interesses específicos, os agentes sociais devem identificar e legitimar regras definidoras do campo que dão sustentação a um "habitus". Em seus termos:

Habitus é um sistema de disposições adquiridas pela aprendizagem implícita ou explícita que funciona como um sistema de esquemas geradores, elaborando estratégias que podem ser pertinentes aos interesses e objetivos dos autores, sem ter sido especificamente projetado para essa finalidade. (BOURDIEU, 2011b, p. 119-120)

Para compreender a especificidade do "habitus" dentro da lógica de um "campo" não é suficiente o conhecimento sobre suas estruturas econômicas e materiais que condicionam determinadas práticas, 
discursos e representações. Também é necessário observar como os agentes sociais reproduzem e ressignificam as mesmas práticas, discursos e representações, dando-lhes um novo sentido que pode colaborar para os objetivos originais em um processo não intencional.

Interpretar a história do esporte a partir deste aporte teórico na Europa foi inicialmente proposto pelo próprio Pierre de Bourdieu em seu texto "Como é possível ser esportivo?", originalmente escrito em 1978. Neste estudo, primeiramente, pretendemos comparar sua análise com as interpretações sobre a introdução dos esportes no Brasil, em específico, na cidade de São Paulo, percorrendo publicações da mídia impressa, em particular, revistas que tematizaram os esportes, e encontravam-se disponíveis no acervo do Arquivo Público do Estado de São Paulo. Ainda como critério de seleção dos documentos, obedecemos ao recorte temporal de 1890 a 1910.

Segundo Martins (2001) neste período em São Paulo foram publicadas revistas e semanários com temática específica dos esportes, quais sejam, "A Bicycleta" de 1896, "O Sportman" de 1902, "A Vida Sportiva" de 1903, "Arte e Sport" de 1903, "O Sport" de 1905, "Sportmen" de 1907.

No acervo do Arquivo Público de São Paulo encontramos "A Bicycleta" e "Arte e Sport".

A revista "A Bicycleta" era publicada em papel jornal semanalmente, e correspondia à revista francesa "Bicyclette". Além da divulgação do ciclismo, também propagandeava a representação de seu dono, Otto Huffenbaecher, sobre a importação das bicicletas de fabricação da empresa francesa Peugeot. (MARTINS, 2001)

Já o "Arte e Sport: semanario de rèclame" era de propriedade de Conrado Egisto Pucciarelli, proprietário do "Teatro Lírico", que via nos amantes dos esportes um público propenso à audiência dos teatros. (MARTINS, 2001)

Contudo outras revistas divulgavam os esportes em seções esportivas, como a revista quinzenal ilustrada "A Vida Moderna", que circulou entre 1907 e 1924. Diferentemente das duas primeiras 
fontes tinha uma influência mais ampla, consolidando-se como importante veículo de informações ligado ao entretenimento na cidade. Neste estudo somente exemplares publicados entre 1907 e 1910 foram analisados.

Outro documento utilizado foi um artigo da "Revista de Ensino" publicação da Associação Beneficiente do Professorado Público de São Paulo que se caracterizava como mídia oficial da Escola Normal. $\mathrm{O}$ artigo tornou-se relevante em nossa análise, pois o seu conteúdo descrevia enfaticamente a criação de uma associação esportiva no âmbito das escolas públicas paulistas, indiciando a pertinência de sua prática no contexto escolar.

$\mathrm{Na}$ análise destes documentos, como limite do estudo, não objetivamos uma história das revistas, como no estudo de Ana Luiza Martins (2001), no qual a pesquisadora descreve as revistas publicadas no primeiro período republicano. Neste texto, elas são analisadas como fontes, e não como objeto de estudo.

Ainda em termos de delimitação, como já apontamos, adotamos o recorte historiográfico de 1890 a 1910. Particularmente o período escolhido representa politicamente a consolidação da república em uma cidade envolta a um processo de crescimento contínuo de sua representação política e econômica no contexto nacional, o que permitiu a disseminação de estruturas esportivas ligadas ao lazer das elites. O que podemos detalhar a seguir.

\section{Uma Paulicéia esportivizada}

No início do século XX as condições estruturais e econômicas do Brasil divergiam das condições europeias. O país desde o final do século XIX passava por transformações com a queda do Estado monárquico. A sociedade civil crescia em complexidade e diversificação dando lugar à emergência de novos setores e "agentes sociais". Do debate intenso entre monarquistas e republicanos, entre um Brasil tradicional e rural e um país moderno e industrializado, no fim do século XIX cresce o interesse por novidades tecnológicas 
próprias da modernidade, e também a tendência de importação de estilos de vida marcadamente europeus que já influenciavam o Rio de Janeiro durante todo o século XIX.

No campo da cultura, uma das manifestações da vida europeia, qual seja, o "ser esportivo", invade as principais cidades brasileiras como tradução de um "habitus" ligado à modernidade. Logicamente, essa influência não foi mecânica, pois sofreu resistências, já que por aqui existiam especificidades que produziam em termos simbólicos novas representações.

Exemplos disto eram as características ecléticas da cultura brasileira que, sem dúvida, colaboraram para uma importação dos esportes mediante uma lógica específica, configurando uma reinterpretação daquelas práticas corporais.

Esse cenário pode explicar as opções de prática esportiva por parte dos brasileiros. No século XIX, nas classes populares havia um interesse importante por jogos e lutas. Os jogos de azar que envolviam apostas, que envolviam animais, refletiam a característica rural da cultura brasileira mesmo nas cidades. Assim, as touradas eram comuns na cidade do Rio de Janeiro, e também, em São Paulo, inclusive com estruturas próprias, que no Rio de Janeiro se localizava no atual Campo de Santana, e em São Paulo, na atual Praça da República (MELO, 2009). Ricardo Lucena (2001) e Andrea Moreno (2003) destacam também a prática da capoeira entre os populares.

Bourdieu (2011a) explica que é uma dimensão privilegiada do "habitus"que distingue as classes populares das classes privilegiadas, a relação instrumental com o próprio corpo. As classes populares preferem as práticas que têm o corpo como objeto de disputas, ou que demandam um grande investimento de esforços, às vezes de dor e sofrimento, e em certos casos exigem que o próprio corpo seja colocado em risco.

Em contraposição, as práticas ligadas às atividades físicas por parte da elite tinham um alto grau de diferenciação. Contudo no Brasil podemos observar que os limites entre o popular e o elitizado eram mais tênues. Já que a participação das elites em atividades 
populares era mais comum. Por exemplo, as touradas incialmente eram festividades em homenagem à família real, além de serem incentivadas pela corte portuguesa. (MELO, 2009)

Somente a partir do final século XIX o discurso de urbanização, modernização, construiu críticas aos jogos populares, às touradas, aos jogos de azar, e à própria capoeira. As elites criticavam a capoeiragem como forte degradadora dos valores humanos, como obra dos setores primitivos da sociedade brasileira, afirmando sua diferenciação. (LUCENA, 2001)

Concomitantemente os intelectuais criticavam o passado rural, atacando a monarquia, anunciando a modernidade. Os republicanos projetavam um novo país, um Brasil moderno nos moldes europeus.

São Paulo representava esta intenção, sem perdemos de vista seu caráter cultural multifacetado. Em outras palavras, uma cidade de sobreposição de diversas culturas. No fim do século XIX e início do século XX, São Paulo era uma das maiores cidades de imigração do mundo (HALL, 2004, p. 121). Segundo dados levantados pela pesquisa de Michael Hall (2004), em 1893 a cidade tinha em sua população mais estrangeiros do que brasileiros (54,6\%). Tendência que permaneceu até os anos de 1930, quando $67 \%$ dos paulistanos eram estrangeiros ou filhos de estrangeiros.

Uma cidade sustentada por uma economia cafeeira, onde o volume de café exportado pelo porto de Santos cresceu de 2,5 milhões de sacas em 1888-89 para 7,8 milhões de sacas em 1900-1901 (SAEZ, 2004). Esse crescimento nas atividades econômicas sustentou também o crescimento de uma burguesia ligada ao café, que por sua vez se identificava com a tradição do campo, mas também aspirava pela ostentação dos códigos de distinção que a modernidade trazia.

Já no final do século XIX, a cidade ostentava o conforto da energia elétrica, promovido pela instalação no país da empresa canadense "The São Paulo Light and Power Company"; e da iluminação pública a gás. (SAEZ, 2004; MOTA, 2003) 
Nesta época as práticas esportivas inglesas ganharam mais adeptos no Brasil, em um cenário de busca da modernidade e do urbano. No período duas modalidades eram mais notórias entre as elites no Rio de Janeiro: o turfe e o remo. (LUCENA, 2001; MELO, 2001)

Para Melo (2009), o turfe tinha destaque por possibilitar uma transição entre duas representações dos brasileiros, pois estaria entre o moderno e o tradicional. Seria moderno com seus termos ingleses, com a espetacularização do evento esportivo, com as associações, com o convívio social das elites, mas ao mesmo tempo tinha a marca do Brasil rural, das apostas, do jogo de azar, da inatividade física, já que a elite era espectadora e não praticante. Por isso no Brasil, diferentemente, da Inglaterra, o esporte sofria múltiplas influências, em um forte ecletismo cultural com tendências em disputa na constituição do campo.

Se pensarmos no turfe em São Paulo, podemos perceber elementos constitutivos de uma decadência nas representações deste esporte para a elite paulistana. Na revista ilustrada paulistana "A Vida Moderna" os problemas do turfe na cidade são evidenciados. Em seus termos:

Depois de uma serie enorme de acontecimentos, de reformas sobre reformas, parece-nos que iremos pouco a pouco, ganhar novamente o renome que outrora tivemos perante as sociedades congeneres. No principio deste anno tivemos bem boas reuniões, mas, foi depois das ferias, isto é, de Setembro em diante, quando se reabriram os portões do pittoresco prado da Moóca, que ellas se tornaram mais concorridas, e mesmo os programmas começaram a ser feitos em melhores condições e os pareos disputados com mais lisura.

Houve tentativas de abusos por parte de pessoas pouco escrupulosas que, projectando actos pouco honestos, tinham como único fito desmoralisar o turf paulista, mas esses planos foram frustrados, porque alguns cavalheiros distinctos e verdadeiros adeptos do turf, procuraram logo cortar o mal pela raiz. [...]

Movimento, Porto Alegre, v. 19, n. 04, p. 95-117, out/dez de 2013. 
Esperamos e desejamos que elle siga sempre em progresso cada vez mais crescente para que possamos em breve ser os mesmos que outr'ora engrandecemos o hyppismo brasileiro. (TURF, 1907b, p. 20)

Particularmente, este número da revista "A Vida Moderna", publicado no dia 25 de dezembro de 1907, tinha como mote uma retrospectiva sobre os principais acontecimentos esportivos do ano. $\mathrm{Na}$ visão da revista, o turfe paulista naquele ano havia iniciado um processo de recuperação, pois o esporte apresentava características decadentes desde o início do século XX. A chamada tradição paulista naquele esporte deveria ser retomada, o que significava o aumento de sua prática, sem, contudo, ferir os princípios morais definidos por regras, códigos, e simbolismos pertinentes à postura de uma determinada classe social. $\mathrm{O}$ que ainda causava orgulho na elite paulistana não estava apenas nas corridas em si, mas principalmente, na convivência com um público seleto que ostentava o Jockey: "Regorgitam de distinctos cavalheiros dedicados ao soberbo Sport e de senhoras e senhoritas da nossa mais fina sociedade as archibancadas do nosso veterano Jockey Club, em cada reunião organisada." (TURF, 1907b, p. 20)

No início do século XX, na versão paulistana da "belle époque", as práticas esportivas tinham uma representação intimamente ligada ao lazer, ao tempo livre, enfim, aos divertimentos. Embora tenhamos que destacar que em colégios estrangeiros, principalmente de origem norte-americana, como exemplo, o Collegio Mackenzie, o esporte também tinha importância no currículo. Mas eram nas associações e clubes que o esporte, entre as classes altas e médias paulistanas, formou primeiramente um "habitus".

Uma socialização específica das elites acontecia nos clubes esportivos privados, bem como nos cafés, teatros, cinemas, restaurantes, em uma atmosfera inspirada nos hábitos europeus. A vida fechada das fazendas era substituída pela oportunidade da convivência pública em espaços como praças e passeios públicos. (RAGO, 2004) 
A convivência entre as famílias de elite paulistanas em espaços públicos e privados na cidade colaborou com a representação dos esportes e das artes como lazer, como exclusivos e distintivos modos de prazer. Os esportes e as artes eram associados ao espetáculo, e muitas vezes eram identificados como manifestações culturais muito próximas. Exemplo disto foi a criação de um semanário especializado em divertimentos, o "Arte e Sport", que circulou pela primeira vez na capital paulista em 1903. Em seu primeiro editorial intitulado "Duas Palavras", destaca:

Com a fundação do "Arte e Sport" que hoje desce á arena da impressa, abroquelado na certeza de que vem preencher uma grande lacuna - dois são os fins a que nos propomos. O primeiro é offerecer ao Commercio paulistano um órgão de "rèclame" em condições de desempenhar galhardamente seu desideratum; o segundo, proporcionar a todos aquelles que se interessam pelas coisas de Sport um semanario bem feito, que faça jús á maior diffusão possivel. [...] Alem d'isto, o interesse cada vez mais accentuado que nossa sociedade se manifesta pelas diversões artisticas e sportivas, leva-nos a crer que seremos bem recebidos. (DUAS PALAVRAS, 1903a, p. 1)

Ao fazermos a crítica da fonte, constamos que o semanário foi concebido para um público específico, diferenciado, de comerciantes que tinham as artes ou esportes como passatempo. Deste modo, ele não se interessava por práticas populares, mas sim, pelos esportes e artes que representassem uma diferenciação social, uma distinção de classe. Com isso, descritos os limites desta fonte, ele retratava as produções de teatro, música, literatura, turfe, futebol, ciclismo, esgrima e remo. Essas artes e práticas formavam o escopo do semanário, e nos fornecem indícios sobre a ocupação do tempo livre por parte das classes altas e médias de São Paulo.

No "Arte e Sport", em relação ao ciclismo, evidenciamos anúncios para a manutenção das bicicletas, bem como, notícias sobre desafios ciclísticos entre profissionais e amadores envolvendo apostas. As corridas ocorriam em estruturas físicas próprias, como 
o "Velodromo Paulistano", construído em 1892, e demolido em 1916, que também foi palco de importantes partidas de futebol no início do século XX que tiveram Charles Miller como um dos protagonistas. O estádio construído inicialmente para ser sede do "Veloce-Club", ficava próximo à Rua da Consolação, entre o que é hoje a Rua Nestor Pestana e a Rua Martinho Prado, no centro de São Paulo.

Da mesma forma que o turfe atraía um público interessado nos jogos de azar, em divertimentos por parte de um público seleto, o ciclismo também chamava a atenção da elite paulistana, contribuindo assim para a convivência de uma elite mais ampla na qual seus integrantes tinham papéis delimitadamente específicos.

Podemos observar aspectos interessantes em relação ao cenário que envolvia o ciclismo na cidade a partir de uma revista denominada "A Bicycleta" que circulou no final do século XIX:

Extraordinariamente animada a corrida que o " Veloce Club " realisou domingo ultimo, no Velodromo da Consolação, e pena foi que a chuva viesse transtornar a festa, na occasião de realisaremse os pareôs mais importantes do dia. A concurrencia, como sempre, foi selecta, vendo-se nas archibancadas as principaes famílias de nossa sociedade. Durante todo o tempo que durou o temporal, a banda de musica do corpo de bombeiros, collocada numa das archibancadas, executou brilhantes peças. (VELOCE..., 1896c, p. 69)

Eram comuns nas revistas paulistanas, fotografias e ilustrações que retratavam o público do velódromo, evidenciando a promoção do esporte como espaço de convívio das elites e da presença numerosa das mulheres nas arquibancadas.

Margareth Rago (2004) narra que embora as mulheres competissem em alguns esportes, em sua maioria, a prática se constituiu como marcadamente masculina. Assim cabia às mulheres a ornamentação do público, e aos homens a realização de feitos e recordes. Se as representações sobre a mulher no esporte davamlhe o papel de espectadora, também não faltaram exemplos de tentativas de mudança em relação a este aspecto, anunciando o 
moderno, o novo, onde mulheres poderiam ser incentivadas à prática de alguns esportes como o ciclismo. "A Bicycleta" tentava apoiar sistematicamente esta intenção. Nada mais coerente com os princípios da modernidade, onde as mulheres poderiam praticar ginástica, e porque não o ciclismo. A revista adota este pressuposto para criticar fato ocorrido no "Derby Club" da cidade do Rio de Janeiro. Em seus termos:

N'uma corrida do Derby-Club, realisada em princípiosdo mez passado deu-se o seguinte degradante facto, conforme narra 0 Paiz: "Nas corridas do Derby-Club esteve uma moça que fez a sua entrada no prado montando garbosamente uma bicycleta e trajando o amplo vestuário próprio das bicycletistas, espécie de bombachas presas abaixo do joelho, e que não deixam de ter bastante elegância. O facto, porém, constituía uma novidade, entre nós, e o povinho,- cheio de indiscreta curiosidade, começou a fazer grandes ajuntamentos em torno da moça bicycletista, atormentando-a com uma attenção impertinente. Até ahi, nota-se de irregular que o povo não compreendesse a falta de irreverência que estava commettendo e que desse tão triste cópia dos seus conhecimentos do mundo, achando uma coisa talvez fantástica a presença de uma bicycletista n'um campo de sport. A cousa, porem, tomou mais graves proporções. Uma chusma de garotos começou a vaiar a moça, perseguindo-a mesmo, procurando inutilisar-lhe a bicycleta e obrigando-a por fim a refugiar-se no encilhamento e a fugir do prado a toda velocidade da elegante machina que montava. Ha ahi, além do attestado de uma falta de educação inqualificável, um attentado á liberdade individual e a policia tinha o dever de intervir, defendendo a moça vexada e insultada gratuitamente. Pois não o fez, deixando á garotada plena liberdade de acção. Sem commentarios!" (SEM COMMENTARIOS, 1896b, p. 72)

O incentivo por parte da revista à prática feminina do ciclismo traduzia-se também na seguinte passagem: "Consta-nos que duas senhoritas da elite de nossa sociedade, já fizeram encommenda de 
duas bicycletas; algumas outras moças sabendo d'isto, resolveram aprender a andar de bicycleta e a ser isto verdade, folgamos sinceramente dando os nossos parabéns ás duas gentis iniciadoras." (NOTA, 1896a, p. 16)

No final do século XIX e início do século XX havia um discurso médico favorável à prática de esportes por parte das mulheres com objetivos eugênicos (GOELLNER; VOTRE; PINHEIRO, 2012). Logo, os agentes sociais envolvidos com a constituição do campo esportivo adotam o mesmo pressuposto, colaborando na disseminação dos esportes entre as mulheres, como observamos no caso do ciclismo na revista "A Bicycleta".

Outro aspecto importante para o entendimento do ciclismo era sua representação simbólica da modernidade. A relação entre uma máquina e o homem, entre um produto industrializado, e, para os cientistas da época, uma outra máquina bem mais complexa, o corpo humano, trazia consigo a ideia de superação. Particularmente, a interação entre artificial e natural a partir da mecânica, criava uma representação de superação dos limites do homem com auxílio de mecanismos sofisticados.

As novas máquinas invadiam o cotidiano dos homens em vários aspectos, incluindo o lazer. Ali, o desafio, os esforços físicos, a competição, as vestimentas, o equipamento, a premiação, produziam um sentimento de diferenciação próprio de um capital específico disputado pelo homem moderno. Em um esporte moderno, como o ciclismo, importava a excelência pelo tempo, desempenho, precisão, aferidos por uma codificação de escala internacional (SEVCENKO, 1994).

Toda esta atmosfera criou um clima propício à proliferação dos esportes nas classes altas e médias. Sem demora, também a ciência passa a ter interesse pelos esportes, tanto na Europa como no Brasil. Assim os médicos indicavam sua prática mediante alguns cuidados desde o século XIX. Em um artigo intitulado "A bicycleta sob o ponto de vista da Medicina", publicado em 1903, alerta o semanário "Arte e Sport": 
Depois de considerar o assumpto em detalhe, o Dr. H. Irant Sigman offerece as seguintes suggestões acerca do uso da bicycleta.

1- Faça-se uso moderado da montaria, e evite-se todo esforço excessivo, como seja o subir montes íngremes, correr á grande velocidade, etc. Em cada caso esta moderação deve estabelecer-se de accordo com a edade, temperamento e aptidão physica faculdade de tolerância do cyclista. 2- Faça-se a corrida com o corpo aprumado. 3- Apeie-se e descanse-se quando se sentir fadiga ou falta de fôlego. 4- Não se use a bicycleta immediatamente a banquets, isto é, com o estômago cheio. 5- O traje deve adaptar-se faccilmente ao corpo, de modo a não oferecer obstaculo algum ao livre movimento do cyclista. 6- Depois de cada corrida, tome-se um banho de esponja e mude-se a roupa, especialmente roupa interior. De preferencia use-se roupa interior ligeira, de lã, emquanto se faz a corrida. 7- Para viagem longa, deve-se comer a miudo, mas as comidas devem ser leves e nutrientes; evite-se o uso de estimulantes, pois esses embolariam as sensibilidades e fariam o cyclista apreciar menos o cansaço, d"este modo dando-lhe causa a inconscientemente sobrecarregar suas faculdades de tolerância. 8- Em enfermidades de qualquer caracter, não se usa nunca bicycleta, antes de consultar um medico, e se este recomendala, deve haver muita prudência quanto á forma de exercicio que o cyclista tem a faser. (A BICYCLETA..., 1903b, p. 7)

A necessidade de moderação era a principal orientação médica para a prática de esportes. Por isso a competição exagerada, o desequilíbrio, eram problemas que deviam ser evitados no ponto de vista higiênico.

Concomitantemente, o remo, outro esporte moderno que tinha representações semelhantes ao ciclismo, oferecia também o contato com a prática ao ar livre, com as águas, com a natureza. Daí sua significação como hábito saudável. Os praticantes do remo no fim do século XIX e início do século XX envolviam-se em um "habitus", 
onde o asceticismo do esporte ganhava novos contornos em detrimento ao hedonismo. As relações entre esporte e saúde, e entre corpo saudável e atlético eram lentamente difundidas. $\mathrm{Na}$ cidade moderna, os corpos atléticos deviam ser equilibrados, saudáveis, bem treinados. A cidade devia ser higienizada com boulevares, praças, áreas verdes, prédios amplos e arejados, bem como, seus habitantes com corpos limpos e saudáveis. Este era o projeto de modernidade das principais cidades brasileiras. Para Bourdieu (2011a), a inclinação das classes privilegiadas à "estilização da vida" pode ser reconhecida na tendência em tratar o corpo com um fim, que leva ao culto higienista da "forma", ou na própria aparência do corpo como configuração perceptível.

Se compararmos esse cenário paulistano com o contexto da Inglaterra vitoriana, entenderemos que o acesso à vida esportiva contribuiu para o reconhecimento social de uma burguesia mais ampla, que conjuntamente com a aristocracia viam no esporte uma estratégia de distinção. Pelas pesquisas realizadas por Vigarello e Holt (2008) sobre o esporte inglês no século XIX, os esportistas valorizavam um estilo que se traduzia em determinados códigos, como no sentimento de pertencimento. Pertencer a estes clubes onde a prática esportiva era realizada tornou-se um capital específico, que era distribuído pelas regras de convivência e distinção das elites sociais. Ao estudarmos como as elites paulistanas representavam a prática do remo, observamos que tão relevante quanto os resultados esportivos, era noticiar a prática como uma coluna social, evidenciando a formação e convivência de grupos específicos em determinados espaços. A revista "A Vida Moderna" vislumbra como os clubes de remo estavam envolvidos nestas nuances:

O sport nautico que conta numerosos affeiçoados, fez com que se realisassem explendidas reuniões, onde sempre correu um enthusiamo franco e communicativo. O Esperia foi o que mais festas geraes nos deu, realizando sua annual em junho, á qual concorreram clubs da Capital Federal e assistida por delegados da Federação Brasileira, a quem este club se achava filiado. As festas realisadas pelo $\mathrm{S}$. 
Paulo foram na maioria intimas e semanaes, dedicadas exclusivamente aos seus associados e só duas grandes com o concurso dos remadores de clubs santistas. (ROWING, 1907a, p. 19)

Até o momento, podemos perceber que o esporte moderno sustentava um estilo de vida, interesses comuns, um capital específico, que são influenciados por uma estrutura material de urbanização e crescimento econômico (DOIN et al., 2007). Deparamo-nos no decorrer do século XX, em São Paulo, com a gênese da constituição de um campo que vai se estruturar com a popularização e profissionalização dos esportes modernos engendrados por uma série de disputas pela hegemonia no esporte. Exemplos disto residem nos conflitos que envolveram a profissionalização do futebol em São Paulo, a partir dos anos de 1920 e 30, ou nas regras de segregação, como lembra Margareth Rago (2004), dos clubes de remo que tinham regras restritivas sobre a prática por parte de diversos trabalhadores não identificados com a elite.

No início do século XX, os valores do esporte amador em uma ética pertinente às elites, garantiam a hegemonia do campo. Esta ética envolvia normas de sociabilidade que tinha na representação da vitória honesta e cordial uma moralidade própria. Por exemplo, na comemoração da Proclamação da República em 15 de novembro de 1903, o "Club Internacional" de Santos organizou uma regata de remo, convidando o "Club Hesperia" de São Paulo. "Arte e Sport" noticia o evento sempre enfatizando a admiração e convivência cordial entre as duas agremiações e as duas cidades. No artigo "As regatas de Santos", destacamos:

Muito enthusiasmo despertou esta corrida porque era em honra da data gloriosa de 15 de Novembro. Tomou parte nesse partido o Club Hesperia de S. Paulo com a yole gigs Brazil. Entre os applausos dos amigos e das pessoas presentes o Club Hesperia, obteve a palma da victoria ganhando a primeira medalha de ouro. [...] Aguardavam a sua chegada alem de varios socios, distinctíssimas senhoras da nossa sociedade. A chegada do trem promoveu phreneticos applausos aos vencedores 
do Club Hesperia. [...] O Club Internacional para demonstrar a sua admiração aos socios do Club Hesperia que tão airosamente se sahiram nas ultimas regatas offertou-lhes um lindo tinteiro de prata, art nouveau, com a seguinte dedicatoria. Ao Club Hesperia Lembrança do Club Internacional de Regatas - Santos. (AS REGATAS..., 1903d, p. 1-2)

Todo o potencial dos esportes como representação da modernidade atraiu também um interesse mercadológico por seu consumo (MELO, 2008). As publicações especializadas em esportes constituem-se como base empírica para esta interpretação. $\mathrm{O}$ semanário "Arte e Sport", por exemplo, era distribuído gratuitamente em teatros, cafés e confeitarias todas as semanas. Sua sustentação financeira residia na publicidade. Os jornais esportivos, ou revistas ilustradas que também tematizaram os esportes, apresentavam-se como lugares privilegiados de propaganda.

No "Arte e Sport" observamos uma publicidade direcionada a vários públicos, o que evidencia que o esporte já influenciava a sociedade brasileira de forma mais ampla no início do século XX. A diversidade de serviços oferecida demonstra esta característica. Por exemplo, anúncios de tinturarias, instrumentos musicais, produtos dentários, cabeleireiros, barbeiros, marmorarias, empórios, hotéis, perfumarias, produtos europeus importados, empresas de viagens de navio, fábricas, produtos naturais, comércios de roupas com estilo europeu, cafés, confeitarias, máquinas de costura, gráficas, serviços funerários, fotografia, atestam uma rede de serviços que via nos esportes um campo de interesse dos seus clientes.

Já outros serviços eram mais específicos. Em um deles, o propósito era chamar a atenção de fornecedores de materiais e equipamentos para escolas públicas. Em seus termos:

Ao fornecedor das escolas publicas:

Casa especial para fardamentos com fabrica de bonets dirigida por A. BOGGIANI. Especialidade em bonets para foot-ball, ciclystas - canotagem automóvel - bondes E. de ferro e de viagem. 
Distintivos para sociedades e clubs, bandeiras, estandartes, etc. PREÇOS MODICOS. R. JOSÉ BONIFÁCIO, 35-C. (AO FORNECEDOR..., 1903c, p.7)

A passagem demonstra o crescente interesse de serviços ligados ao esporte, mas também sua introdução em escolas públicas, influenciada pelas práticas esportivas de colégios particulares estrangeiros. Exemplo disto seria a Escola Normal de São Paulo.

A escola era dirigida pelo médico Caetano de Campos desde o final do século XIX. A partir de sua direção a ginástica foi incluída no currículo.

No início do século XX, percebe-se uma influência crescente dos jogos ao ar livre e dos esportes nos programas da disciplina de ginástica. A "Revista de Ensino da Associação Beneficiente do Professorado Publico de São Paulo", mídia especializada e oficial da Escola Normal, noticiou efusivamente a criação de uma associação esportiva das escolas públicas. Em seus termos:

Muitas já são as sociedades sportivas entre nós, e compostas de galhardos moços, corajosos e destemidos, como o attestam as esplendidas victorias que alcançaram nos matchs de foot-ball. Agora, sob a inspiração dos professores públicos de S. Paulo, chefiados pelo incansavel director da Escola Normal, fundou-se mais um club sportivo com o titulo acima [Instituto Paulista de Jogos Escolares], destinado aos exercicios de jogos ao ar livre pelos alumnos e alumnas das nossas escolas publicas e seus respectivos professores, e pelos alumnos da Escola Normal. Não commentamos o beneficio extraordinario que vem prestar tal associação, por isso que está na consciencia de todos, que conhecem a importancia dos jogos ao ar livre, a necessidade de avigorar esses débeis corpos que estiolam nas ruas da cidade, afim de premunil-os das molestias tantas proprias dos centros populosos. Basta-nos dizer apenas que com a energia physica virá a energia moral e a acção, de que tanto precisa o brasileiro [...] (INSTITUTO..., 1902, p. 576-577)

Movimento, Porto Alegre, v. 19, n. 04, p. 95-117, out/dez de 2013. 
Percebemos aqui que o esporte tinha outras ênfases no ambiente escolar, como objetivos morais que residiam em uma formação educacional que podia ser transportada para outras esferas, como a higiene urbana, a saúde individual, o nacionalismo e o sentimento de pertencimento.

Por isso o esporte imprimia no corpo não somente as marcas do esforço, das vestimentas, da indumentária, do estilo moderno e saudável, mas também, de uma moralidade envolta em um "habitus" propriamente esportivo, presente em diversas instituições como clubes, exércitos e escolas.

Assistimos durante todo o século XX a consolidação deste "habitus", que, atualmente, é tão influente que na análise de Soares e Brandão (2012, p. 13): "O modelo esportivo invade a vida cotidiana, as escolas, as empresas, os lares e toda uma expectativa de educação do corpo, de saúde e, no limite, da vida, se constitui a partir deste modelo."

\section{Considerações finaIS}

Em São Paulo, no fim do século XIX e início do século XX, na cidade que crescia, que se tornava moderna, que recebia diferentes culturas, todas imbricadas em uma concretude ímpar, o esporte teve como característica a aglutinação de determinados grupos que capitalizam determinadas regras e normas sociais. Assim o esporte era uma das manifestações culturais capazes de produzir códigos de distinção marcadamente modernos, mas que no contexto paulistano tinham também a especificidade de manutenção de grupos exclusivos, que concomitantemente, ofereciam eventos que possibilitavam o convívio com outros grupos, ou com elites mais amplas. Além disso, a capacidade de promoção do consumo das práticas esportivas foi explorada pelas mídias analisadas, que viam na disseminação dos esportes, oportunidades de ampliação do mercado consumidor. Novos e velhos produtos manufaturados, pertencentes ou não ao universo esportivo eram propagandeados na nova cidade moderna. Portanto entre os códigos e normas para a 
obtenção de um capital específico e exclusivo de delimitados grupos, havia, ao mesmo tempo, condições materiais e econômicas para a ampliação do consumo, formando elites mais amplas que se encontravam em praças esportivas, predominantemente, estabelecidas em clubes privados.

Os clubes esportivos eram os espaços de sociabilidade destes grupos sociais, e neles, papéis específicos eram reservados a determinados agentes mediante sua posição social, como exemplificamos com o caso das mulheres.

Em São Paulo, o urbano se impunha, ou seja, as condições estruturais tornaram-se mais favoráveis à introdução não só dos esportes ingleses, como ciclismo, remo, futebol, mas também, norteamericanos como o voleibol, basquetebol, que se opunham e disputavam espaço na constituição do campo esportivo com as ginásticas de origem alemã, sueca e francesa, que por sua vez disputavam espaços com atividades de origem popular. Havia na Paulicéia, defensores e críticos de todas estas práticas, envoltos em um ecletismo cultural que ressignificou os esportes, mesmo tendo como parâmetro a modernidade europeia.

Durante todo o século XX, os brasileiros assistiram a constituição deste campo esportivo, que para Bourdieu (2011a) envolve a indústria esportiva, os profissionais do esporte, da educação física, da ginástica, os atletas, médicos, políticos, professores, enfim, diversos "agentes sociais" em luta pelo poder. Ao realizar esta análise Bourdieu (2011a) propõe também uma grande agenda de pesquisa para a história do esporte que envolve o princípio das transformações das práticas e dos consumos esportivos; a invenção ou importação de esportes ou de equipamentos novos; as lutas pela imposição da prática esportiva legítima; lutas entre diferentes esportes e, no interior de cada esporte, entre as diferentes escolas ou tradições; lutas entre as diferentes categorias de agentes engajados nesta concorrência; a transformação dos estilos de vida. Enfim, uma agenda muito extensa. 


\section{The Sport and the modernity in São Paulo: corporal practices at the turn of the 20th century Abstract: The objective of this study was to understand how sports were appropriated in Brazil, particularly in São Paulo at the turn of the 20th century. For this, we used as sources: newspapers and magazines that thematized the sport during the study period. Concluded that in the context of the Brazilian culture, the sports were reinterpreted, even though the parameter of European modernity. \\ Key-words: History. Sport. Brazil. São Paulo City.}

El Deporte y la modernidad en São Paulo: practicas corporales en final del siglo XIX y comienzo del siglo $\mathrm{XX}$

Resumen: El objetivo de este estudio fue entender cómo el Brasil reinterpretó los deportes, particularmente en São Paulo a fines del siglo XIX y comienzo del XX. Para ello, se utilizan como fuentes: periódicos y revistas que tuvo como tema el deporte durante el período de estudio. Concluyó que en el contexto cultural brasileño, deportes fueron reinterpretados, a pesar de la influencia de la modernidad europea.

Palabras-clave: Historia. Deporte. Brasil. São Paulo.

\section{REFERÊNCIAS}

A BICYCLETA sob o ponto de vista medico. Arte e Sport: semanario de reclame, São Paulo, v. 1, n. 3, p. 7, 1903b.

BOURDIEU, Pierre. Coisas ditas. São Paulo: Braziliense, 1990.

BOURDIEU, Pierre. Comment peut-on être sportif? In: BOURDIEU, P. Question de sociologie. Paris: Les Éditions de Minuit, 2011a. p. 173-195.

BOURDIEU, Pierre. Quelques proprieties des champs. In: BOURDIEU, P. Question de sociologie. Paris: Les Éditions de Minuit, 2011b. p. 113-120.

DOIN, José Evaldo de Mello et al. A Belle Époque caipira: problematizações e oportunidades interpretativas da modernidade e urbanização no Mundo do Café (1852-1930) - a proposta do Cemumc. Revista Brasileira de História, São Paulo, v. 27, n. 53 , p. $91-122$, jun. 2007.

DUAS Palavras. Arte e Sport: semanario de reclame, São Paulo, v. 1, n. 1, p. 1, 1903a. 
DUNNING, Eric; ELIAS, Norbert. A busca da excitação. Lisboa: Difel, 1992.

AO FORNECEDOR das escolas publicas. Arte e Sport: semanario de reclame, São Paulo, v. 1, n.1, p. 7, 1903c.

GOELLNER, Silvana Vilodre; VOTRE, Sebastiao Josue; PINHEIRO, Maria Claudia Brandao. Strong mothers make strong children: sports, eugenics and nationalism in Brazil at the beginning of the twentieth century. Sport, Education and Society, London, v. 17, n. 4, p. 555-570, ago. 2012.

HALL, Michael. Imigrantes na cidade de São Paulo. In: PORTA, P. (Org.). História da cidade de São Paulo. São Paulo: Paz e Terra, 2004. v. 3, p. 121-152.

INSTITUTO Paulista de Jogos Escolares. Revista de Ensino da Associação Beneficiente do Professorado Publico de S. Paulo, São Paulo, v. 1, n. 1, p. 576-577, abr. 1902.

LUCENA, Ricardo Figueiredo. O esporte na cidade. Campinas: Autores Associados, 2001.

MARTINS, Ana Luiza. Revistas em revista: imprensa e práticas em tempo de República, São Paulo, 1890-1922. São Paulo: Edusp; Fapesp, 2001.

MELO, Victor Andrade de. Cidade sportiva: primórdios do esporte no Rio de Janeiro. Rio de Janeiro: Relume Durama, 2001.

MELO, Victor Andrade de. Das touradas às corridas de cavalo e regatas: primeiros momentos da configuração do campo esportivo no Brasil. In: PRIORE, M.; MELO, V. A. (Org.). História do esporte no Brasil. São Paulo: Edunesp, 2009. p. 35-70.

MELO, Victor Andrade de. Esporte, Propaganda e publicidade no Rio de Janeiro na transição dos séculos XIX e XX. Revista Brasileira e Ciências do Esporte, Campinas, v. 29, n. 3, p. 25-40, maio. 2008.

MORENO, Andrea. O Rio de Janeiro e o corpo do homem fluminense: o "não lugar" da ginástica sueca. Revista Brasileira de Ciências do Esporte, Campinas, v. 25 , n. 1, p. 55-68, set. 2003.

MOTA, Carlos Guilherme. São Paulo: exercício de memória. Estudos Avançados, São Paulo, v. 17, n. 48, p. 241-263. 2003.

NOTA. A Bicycleta, São Paulo, v.1, n. 4, p. 16, 1896a.

QUITZAU, Evelise Amgarten; SOARES, Carmen Lucia. A força da juventude garante o futuro de um povo: a educação do corpo no Sport Club Germania (1899-1938). Movimento, Porto Alegre, v. 16, n. 3, p. 89-108, jul./set. 2010.

RAGO, Margareth. A invenção do cotidiano na metrópole: sociabilidade e lazer em São Paulo, 1900-1950. In: PORTA, P. (Org.). História da cidade de São Paulo. São Paulo: Paz e Terra, 2004. v. 3, p. 387-436. 
AS REGATAS de Santos. Arte e Sport: semanario de reclame, São Paulo, v. 1, n. 3, p. 1-2, 1903d.

ROWING. A Vida Moderna: revista quinzenal illustrada, São Paulo, v. 2, n. 29, p. 19, 1907a.

SAEZ, Flávio. São Paulo republicana: vida econômica. In: PORTA, P. (Org.). História da cidade de São Paulo. São Paulo: Paz e Terra, 2004. v.3, p. 215-258.

SEM Commentarios. A Bicycleta, São Paulo, v.1, n. 18, p. 72, 1896b.

SEVCENKO, Nicolau. Futebol, metrópoles e desatinos. Revista USP, São Paulo, n. 22, p. 30-37, jun./ago. 1994.

SOARES, Carmen Lucia; BRANDÃO, Leonardo. A voga esportiva e as artimanhas do corpo. Movimento, Porto Alegre, v. 18, n. 3, p. 11-26, jul./set. 2012.

TURF. A Vida Moderna: revista quinzenal illustrada, São Paulo, v. 2, n. 29, p. 20, 1907b.

VELOCE Clube. A Bicycleta, São Paulo, v. 1, n.18, p. 69, 1896c.

VIGARELLO, Georges; HOLT, Richard. O corpo trabalhado: ginastas e esportistas no século XIX. In: CORBIN, A; COURTINE, J.; VIGARELLO, G. A história do corpo. Petrópolis: Vozes, 2008. v.2, p. 393-478.

Fontes

A BICYCLETA. São Paulo, 1896-1896. Semanal.

ARTE E SPORT. São Paulo, 1903-1903. Semanal.

A VIDA MODERNA. São Paulo, 1907-1924. Quinzenal.

Endereço para correspondência:

Edivaldo Gois Junior

Departamento de Educação Física e Humanidades

Av. Érico Veríssimo, 701. Cidade Universitária.

Campinas, São Paulo.

CEP 13083-851 - fone: (19) 35216618

Recebido em: 04.03.2013

Aprovado em: 03.06.2013

Movimento, Porto Alegre, v. 19, n. 04, p. 95-117, out/dez de 2013. 